\section{AWARENESS OF SELF AND THE ENGINEERING FIELD: STUDENT MOTIVATION, ASSESSMENT OF 'FIT' AND PREPAREDNESS FOR ENGINEERING EDUCATION}

\author{
Claudia Bennett, Minha R. Ha, Julian Bennett and \\ Aleksander Czekanski \\ Mechanical Engineering, Lassonde School of \\ Engineering \\ bennet37@yorku.ca,minhareo@yorku.ca
}

\begin{abstract}
Understanding factors that influence incoming students' preparedness and success is critical in improving educational efficacy. Students' prior experiences, assumptions, and habits influence their engagement in process of learning to become competent design engineers. A thematic analysis of students' reasons for pursuing an engineering major revealed such decisions to be based on self-assessed personal fit. This paper indicates four common types of personal fit as described by students: matching skillsets, desirable activities, meaningful impact, and exploratory intrigue. From these, two key factors emerged: an awareness of self (ie. skills, interests, values) and an awareness of the engineering field (ie. nature of its work, its value to society, its value to the individual). These factors were influenced by: prior academic performance in core courses, authoritarian influence and the presence of engineers within their social networks. The paper also discusses incoming students' perception of design engineering attributes as revealed in their survey responses. We argue that efforts are needed to provide students, before and during university, with opportunities to engage with career engineers or engineering exercises in order for them to be able to accurately establish an understanding of the engineering field, negotiate expected learning outcomes, master effective strategies to succeed, assess their strengths and limitations. The data are drawn from a larger study on student motivation and learning process in design engineering education.
\end{abstract}

Keywords: Preparedness; Motivation; Self-assessment of fit; Personal fit; Awareness of self

\section{INTRODUCTION}

Despite the increased interest in students pursuing the engineering field and increased academic interest in engineering education research, there remains a particular need to address underpreparedness, attrition and varied success of learners in their academic endeavors and career plans (Woollacott, 2009). In terms of students' achievement and persistence to succeed in engineering, literature suggests that the motivational constructs (including expectations and value-based beliefs) and the behavioural constructs (including learning strategies) both play an important role (Jones, Paretti, Hein \& Knott, 2010; Biggs, 1999; Biggs, Kember \& Leung, 2001). Often, much attention is paid to how learner behaviours might change throughout their engineering program; however, less attention is paid to how engineering education connects to the learner's motivations to actually engage with the learning process. Contemporary engineering students approach learning through contrasting learning profiles, as a result, curriculum in engineering must adjust from previously successful models to those more diversely accommodating to today's variety engineering students (Biggs, 1999).

In this paper, we explore the question: What motivates students to choose engineering? The discovery includes several overarching themes. First, there is the reasoning that students use to choose engineering, which include motivational constructs such as: self-efficacy, intrinsic interest, extrinsic utility, attainment of personal values, and self-identification with being an engineer (Jones et al., 2010). Secondly, there are distinct knowledge categories that establish each motivational construct, namely: knowledge of self, knowledge of the engineering field. These knowledge categories are expected to inform the reasoning used in the student's' choice of educational major.

We attempt to connect the two knowledge categories (of self and of the engineering field) to the concept of preparedness (Woollacott, 2009). We define preparedness as the self-assessed and actual readiness contributing to the ability to succeed in engineering. If the motivation to choose engineering reasonably assumes an expectation to succeed in engineering, which skills and qualities do students identify in themselves? How does the understanding of the engineering field influence such self-assessment, which may affect the learner's decision to pursue engineering? 
Proc. 2016 Canadian Engineering Education Association (CEEA16) Conf. Self-assessment of the learners' qualities and competencies: Since students are spending time and energy on what it is they perceive as the more important aspects of their learning, there needs to be a mutual understanding between the instructors and students on the goals and strategies for educational success in order to best accomplish learning milestones. Students' competencies include the ability to learn: 'deep' or 'surface' learning strategies; the ability to work independently as well as working with others; and the ability to solve open-ended, multidisciplinary problems.

Knowledge of the engineering field: There is a suggested relationship between: understanding the nature of the engineering field, understanding the requirements to succeed in engineering, and setting educational goals in order to develop the required competencies and attributes (Braskamp, 2009; Woollacott, 2009). This may apply not only to engineering programs, but also to learners who set their own educational goals. Against the backdrop of the known success competencies in engineering, students may self-assess their progress, set learning goals, and apply learning strategies towards their attainment. It is important, then, to understand the students' prior conceptualizations of engineering, what shapes such conceptualizations, and to what extent these prior understanding influences the learners' behaviour and achievement during the undergraduate program. Program strategies will need to effectively respond to any gaps in the student's' expected learning objectives and learning behaviours, from cohort to cohort. With better understanding of each incoming cohort's knowledge, engineering curriculum will be better programmed to fit undergraduate students with appropriate foundational courses that are critical to future success (Nelson, 2015).

This paper is drawn from a larger study on design engineering education at York University. This paper examines first year students' motivations behind choosing an engineering major, and also their selfassessment of the skillsets that may contribute to their success in engineering. Data for this paper are drawn from an entrance survey and focus group data. The entrance survey was completed by 12 first year students from all programs within the engineering department at York University and consisted of open-ended written response questions and rating items. The written responses were quantified using thematic analysis and the rating questions were categorized and compared with the Likert-scale response rates. The focus group was conducted with three second year students in Mechanical Engineering who had been participants in the entrance survey the previous year. The focus group was conducted in in three sessions, the first of which was conducted with all three students, Subsequent focus groups were performed in a one-on-one manner.

\section{STUDENT MOTIVATION AND REASONING}

\subsection{Self-assessment of FIT}

The responses to the first open-ended question, "Why did you choose engineering as a major?” provided us with basic student reasoning behind choosing engineering. Overall, students consistently linked the reason for engineering studies to their understanding of themselves. Such understanding included four distinct aspects of their individuality: a) matching skillsets ("I'm a math person," "Interest in computers, enjoy coding, and dealing with hardware"); b) desirable regular activities ("I love the idea of inventing things," "I love working on projects with people”); c) meaningful impact of the work ("I want to work in a field where solving problems would benefit the community," "Working towards advanced technological evolution is one of my dreams"); and d) exploratory intrigue ("I love the concept of space”). All four categories carry implicit understanding or expectations of what engineering work involves, and what it means to personally associate with the role of being an engineer.

For some students, discovery and exploration of physical phenomena were important motivators to pursuing engineering studies. This exploratory inclination of students is discernibly linked to the nature of engineering. Surprisingly though, several students noted their lack of confidence in their creativity and innovative skills which are fundamental in design engineering; $50 \%$ of respondents disagreed that they are confident in their self-assessed design skills and 33\% of respondents disagreed that they are confident in their selfassessed creativity skills. Related skillsets were infrequently attributed to as reasoning or motivations for pursuing engineering. Most students felt strongly about their self-assessed logical aptitudes as $83 \%$ of students agreed that they self-assess themselves as mechanically inclined, 67\% agreed that they self-assess themselves as technically inclined. Correspondingly, we found students rating their confidence levels to be high in similar subject area as $82 \%$ rated themselves confident or highly confident in physics, 92\% rated themselves as confident or highly confident in mathematics and $100 \%$ rated themselves as confident or highly confident in 
Proc. 2016 Canadian Engineering Education Association (CEEA16) Conf.

engineering. Although self-assessed high confidence in these areas are good indications of students predispositions to like their major, these results do not inform us of the level of preparedness their self-assessed skills are in terms of their readiness for an engineering major. It has been expressed that there remain deficiency in students' knowledge and cognizance in personal and interpersonal skills such that they are unprepared for future professions in engineering, however these dimensions are much harder to develop and determine.

(Braskamp, 2009)

For some students, familial encouragement to pursue engineering as a major was reinforced by relation of someone in their personal social networks previously or presently was working in the field of engineering as was specified in student surveys stating "Father is an engineer, wanted to follow in his footsteps, engineering intrigued me." What we did find to be deficient in acknowledgement were references to the actual quotidian job functions, e.g. working on projects, competing for presence, developing a network of colleagues, participating in teamwork/projects to create their future positively impacting designs and the like.

Overall, these responses suggest that students' motivation for engineering involves a match between (a) their personal interests, values, and/or capabilities; and (b) the expectation that engineering was the right field to exercise or actualize these personal qualities. What shapes students' prior knowledge about engineering is beyond the scope of this paper.

\subsection{Understanding of Self}

The majority of students self-assessed and determined themselves to be fit for success within the engineering field based on their previous academic performances in and enjoyment of mathematics and science courses. Many students sought engineering as a major in which the math and science could be combined. Although not every reported being or feeling full prepared for pursuing an engineering major, these students were of the belief that their intelligence is incremental and would be able to grow and adapt their skills in order to [catch up] with the rest of their cohort (Stump, 2014). In what opportunities, it is also beyond the scope of this paper. Regarding students' self-assessment of skill sets and indication of their personal values, we found the following from the rating questions:

CEEA16; Paper \#56

Dalhousie University; June 19 - 22, 2016
Figure 1. Subject Area Confidence Pre-University

Majority of students had confidence in mathematics and physics. This is consistent with their responses in another part of the survey, indicating that all students (12 of 12) enjoy the subjects of science and mathematics more than they do liberal arts courses. However, nearly $1 / 3$ of the students were experiencing difficulty with chemistry, speaking, and writing courses.

There is a great variation in computer skill-level across the cohort. Focus group data suggested that the variation in computer skills may impact student experience or learning progress in engineering: "Even though I might have been expected to know it, coding on Matlab or Java, I wasn't prepared for it because it wasn't really a prerequisite for anything so I never took coding in high school. I think that was one of the only times that I wasn't so prepared” (Focus Group I). This does not; however, suggest that lack of prior computer training impedes academic performance.

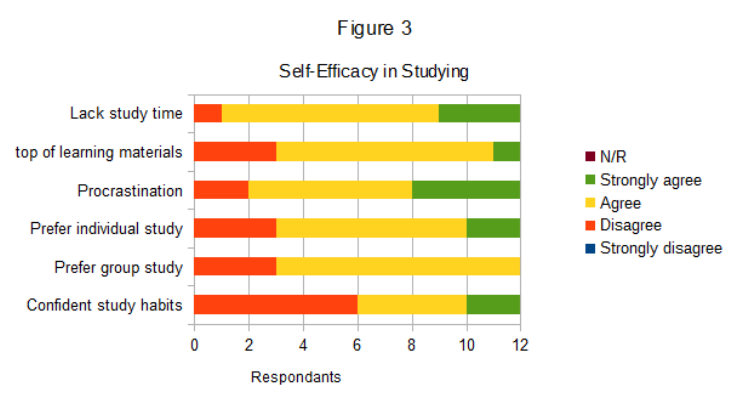

Figure 3. Self-Efficacy in Studying

Most students agreed to a significant level of procrastination (83\%) while also indicating they lacked study time (92\%). Half of the students were not confident

Figure 1

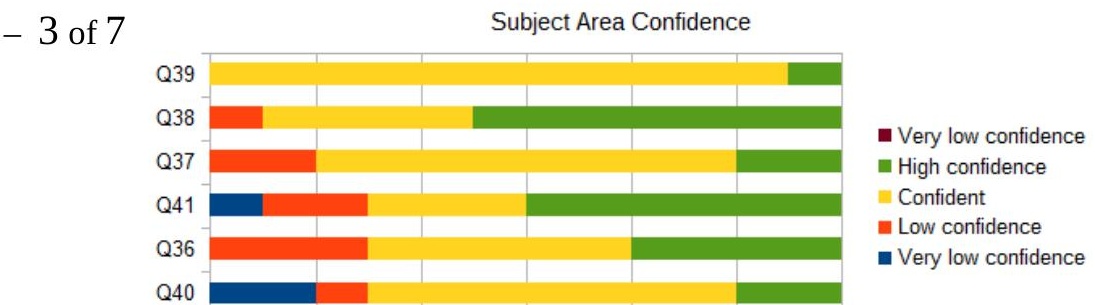


Proc. 2016 Canadian Engineering Education Association (CEEA16) Conf. of their learning (75\%). Such deviation in self-efficacy regarding students studying habits and practices is concerning as each of the practices and conditions above are inextricably linked. The causes for these discrepancies are yet to be explored.

\subsection{Expectations regarding the engineering field}

Figure 4. Economic Value of Engineering Career/Study

Although students associated job security (75\% either agreed or strongly agreed that engineering was a major that would guarantee them a job after graduation) and high income (91\% of students agreed or strongly agreed that they think engineers are paid well) with an engineering career, $75 \%$ of students disagreed that they were motivated to study engineering for financial benefits they could not gain in another profession meaning they did not see engineering as the only option that would guarantee such economic benefit. Removing the economic values as a prime motivators for pursuing engineering, opens up other aspects of the career decision making process.

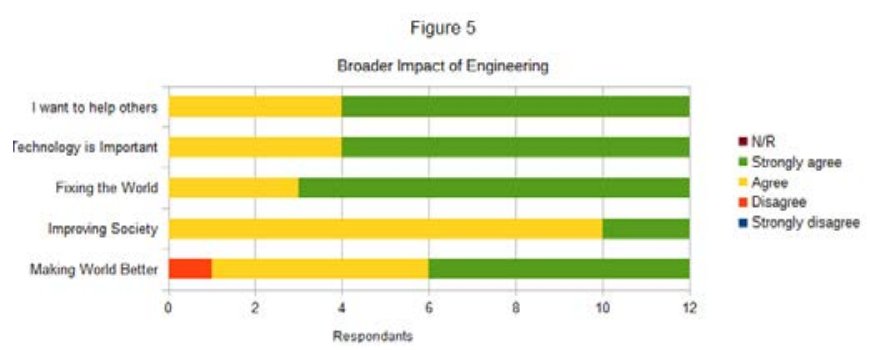

Figure 5. Meaningful Impact of Engineering on Society

There was an overwhelming confidence from student respondents in engineer's' ability and history to serve the public good, more so than other professions. We found $92 \%$ of students agreed or strongly agreed that engineers are well respected by society and $100 \%$ of students agreed or strongly agreed that the nature of engineering is more concerned with society improvements than other profession. This is somewhat consistent with the results of the open-ended question 1 of the survey (Section 2.1), where students expressed having motivations based on the potential positive impact of their future career whether it be environmentally or humanistically. Although such social responsibility is generally thought of as noble, it is important to again ensure students have a well-balanced idea of what the scope of engineering and

CEEA16; Paper \#56

Dalhousie University; June 19 - 22, 2016

-4 of $7-$

its various disciplines can mean and develop into during their careers so that they have appropriate expectations and are able to make well informed self-assessments.

Figure 6. Skills and Characteristics Associated with Being an Engineer

During the survey and focus group procedures, students were asked to identify what attributes, if any, they associate with design engineering and being an engineer in general. Results from the survey of first year engineering students had many similarities in responses, particularity the $66 \%$ participants who used variations of the term creative. Other attributes associated were "innovative, rational, problem solving respected, professionalism, and creative”. These attributes developed over time and during the focus groups, participants who were at the time second year students, had more refined responses. "Designing seems like a simple task... The theory is already understood and everything, but just being able to apply that to the actual situation, I think that's where a lot of us would have and are having difficulty" "It [design engineering] is just not a simple task, there's many different steps that goes into the whole thing." "Design engineering is a part of any field of engineering. If you have a problem, you need to design the solution... you go through the whole process of designing the solution itself...” (Focus Group I).

To complement our analysis, we looked at the focus group data for specific ways students' perception of the engineering field developed. While the full analysis is beyond the scope of this paper, students articulated their previous conception of the engineering field, the changed perceptions, and what caused that change:

Student's interpretation of engineering evolved after being in the program. Their understanding expanded engineering to be an interdisciplinary complex discipline necessitating authentic communication skills, a capability to collaborate with others, fulfill leadership roles, design and create with consideration of human, environmental and social-centric concerns. They additionally expanded that these considerations must be contained within their capability and materials available "They give us complete freedom, do anything you want. Just make it a feasible project...The material, that's the only restraint” (Focus Group I).

Factors that influenced and brought about changes in students' perception and impression of what it is engineering consists of guest speakers through the Engineering as a Profession course in which speakers 
Proc. 2016 Canadian Engineering Education Association (CEEA16) Conf.

from multiple disciplines within the engineering field addressed students given them opportunity to interact "There were a couple who were in those parts of mechanical engineering, and I found them fascinating...The things that they do to help society as engineers is interesting” (Focus Group II Session I); experientially learning the design process through course projects in which students needed to follow a framework of design process, creating a product from conception to production, synergizing within different teams.

\section{DISCUSSION}

\subsection{Value-based motivational constructs and learner development}

There is an important relationship between the students' understanding of themselves and their fit with the expectations regarding an engineering career. The choice of engineering reflects an expression of students' personal interests, values, as well as their competencies. Many students were seeking a career connectedness to value-based constructs (Jones et al., 2010), where one would make a positive contribution to a broader context. In the face of robust debates in engineering ethics (see Davis, 2001), this should challenge educators to better understand what makes the engineering identity meaningful to the students, and the implications on learner development and professional practice.

There is a need to critically examine how learner agency as effective engineers (i.e. in practical, and moral sense) is interconnected with the way educators validate and support learner development in engineering. For example, a previous study found that students valued social responsibility in different levels of priority based on which engineering discipline they were being trained in (Canney, 2015). Is it possible for students to become less oriented towards social responsibility during the university program? If universities are to empower students to become more effective in serving the public as engineers, does the undergraduate program give both a practical and moral guidance on navigating/negotiating conflicting interests and influences (Grenny, Patterson \& Maxfield, 2013)? It should be explored and discussed why and how specific disciplines espouse different value systems, and to what degree the students have an active role in creating the disciplinary culture.

CEEA16; Paper \#56

Dalhousie University; June 19 - 22, 2016
Thus a focus on the learner agency (i.e. their active ways of creating their realities) within the context of university structure (i.e. factors outside the learners' control, that influence or limit agency) places responsibility on the educators to reexamine their role in encouraging and preparing students for success. There are at least two aspects that require the university community's attention:

(1) How are we supporting students' selfreflection and development as learners, citizens, and to-be engineering professionals? If the learners inherently have a vested interest in their development (in multiple identities), then cocreating such meaningful identification may be an important part of positively connecting to the curriculum/course materials (Nelson, 2015). Even the questions we pose to students already embed constructs that can serve as a resource (i.e. help students make sense of their experience) or as constraints (i.e. validate only one way of explaining an experience).

(2) How are we communicating the philosophies, contributions or accomplishments, required competencies and the nature of diverse engineering work, to the public community? Universities need to take an active role and become accountable in understanding the venues by which youths gain their information deemed relevant, and more importantly, how students are also actively involved in the creation and sharing of such information.

\subsection{Factors to successful learning}

A recurring theme noted throughout the research data is that there are inadequate opportunities where students would be enriching or gaining a more comprehensive understanding of what the engineering industry expects of its students and novices in the field. Some students did report struggling in different aspects of the curriculum which was found to be largely due to insufficient prior exposure. Nevertheless, lack of exposure does not equate to incapability; transferable skills could be taught during formative years (Mentzer, 2015; Stump, 2014). A more urgent need is in supporting students' development of evaluation criteria to self-assess and guide their own progress. We need to be more adamant about communicating the goals and expectations clearly and early on, ensuring all students will proceed with comparable foundations to build the rest of their degree upon. Inevitably, it is the students who must actively engage in and change through the learning process 
Proc. 2016 Canadian Engineering Education Association (CEEA16) Conf.

(Beard, 2010). Opportunities to explore and assess one's own capabilities, interests, and motivations as they relate to the career field may be vital to sustaining motivation and persistence through the program.

An equally important discussion may be in creating manageable, effective program workload. Focus group students unanimously agreed that those who enrolled in a course load lighter than the departmental standard were better adept to learn, expand upon and retain new concepts more comprehensively than while previously enrolled in the departmental standard course load. Students also alluded to be able to engage in exploratory intrigue "During the (York) strike, that was actually a good time for us... I was able to catch up on physics... and I did well in that course - only because of the strike. I actually started reading more in depth... So I started learning about other stuff... You get more interested in it and you actually retain that kind of information.” (Focus Group I).

The actionable insight from these findings is in how we orient the first year students. Good teaching is what facilitates and accelerates learning, not by the techniques alone but by what the instructors understand and how they value human learning (Bain, 2004). The contemporary classrooms are made up of a varied body of learners including non-academic committed learners with new and various motivations for their education. With different motivations for learning comes various new approaches to their learning (Biggs, 1999). Partnership between faculty and students has a critical role in understanding and developing both the learner preparedness and program responsiveness to changing learner conditions. Learner preparedness and program responsiveness are just two concepts in the larger picture of university as a learning organization where both instructors and students are constantly learning, adjusting, and strategizing for educational success (Senge, 2006).

\section{CONCLUSION}

The preliminary findings from the entry survey and focus group data suggest that students enter university with varying expectations and learning needs, which the educational program strategies must accurately assess and respond accordingly. First year students generally lacked a realistic understanding of what engineering is, and struggled with building effective study skills. The students were motivated by different values they expected from an engineering career or program; For educators to connect with the learners' prior knowledge and expectations, it would be important for us to understand the contemporary students' frame of reference for engineering, their basis for decision making, and the language and level they are expressing their interests in, and their motivations.

The learners were actively assessing their own skillsets, interests, and values, and comparing them to available disciplines or careers to find the best fit. There needs attention on how the university is helping create public knowledge of the engineering field - the nature of its work, its impact on society, and the qualities required of the engineers for good engineering - before and during university. At the same time, the role and agency of young people should be respected in their diverse ways of making their engineering studies meaningful. The findings in this paper raised more critical questions about the educators' current understanding of the learners, their development processes, and their motivation to pursue and persist in the engineering program.

\section{Acknowledgements}

We would like to extend our gratitude to our various supporters of design engineering education research and the expansion of our horizons. This includes but is not limited to Quanser Inc, Vice Dean Jean Kosinki and the Lassonde School of Engineering at York University.

\section{References}

[1] Ken Bain, What the Best College Teachers Do, 1 edition. Cambridge, Mass: Harvard University Press, 2004.

[2] Colin Beard, The Experiential Learning Toolkit: Blending Practice with Concepts. London; Philadelphia: Kogan Page, 2010.

[3] John Biggs, "What the Student Does: teaching for enhanced learning," Higher Education Research \& Development, vol. 18, no. 1, pp. 57-75, Apr. 1999.

[4] Larry A. Braskamp, "Using a Measure of Student Holistic Development for Quality Assurance,” in Engineering Education Quality Assurance, Arun Patil and Peter Gray, Eds. Boston, MA: Springer US, 2009, pp. 201-209 [Online]. Available: http://link.springer.com/10.1007/9781-4419-0555-0_16. [Accessed: 16-May-2016]

[5] Nathan E. Canney and Angela R. Bielefeldt, "Differences in Engineering Students' Views of Social Responsibility between Disciplines," Journal of Professional Issues in
CEEA16; Paper \#56

Dalhousie University; June 19 - 22, 2016
-6 of $7-$ 
Proc. 2016 Canadian Engineering Education Association (CEEA16) Conf.

Engineering Education and Practice, vol. 141, no. 4, p. 04015004 , Oct. 2015.

[6] Brett D. Jones, Marie C. Paretti, Serge F. Hein, and Tamara W. Knott, "An Analysis of Motivation Constructs with First-Year Engineering Students: Relationships Among Expectancies, Values, Achievement, and Career Plans," Journal of Engineering Education, vol. 99, no. 4, pp. 319336, Oct. 2010.

[7] Nathan Mentzer, Kurt Becker, and Mathias Sutton, 'Engineering Design Thinking: High School Students' Performance and Knowledge: Engineering Design Thinking of High School Students," Journal of Engineering Education, vol. 104, no. 4, pp. 417-432, Oct. 2015.

[8] Matthew Meyer and Sherry Marx, "Engineering Dropouts: A Qualitative Examination of Why Undergraduates Leave Engineering: Engineering Dropouts: Why Undergraduates Leave Engineering," Journal of Engineering Education, vol. 103, no. 4, pp. 525-548, Oct. 2014.

[9] Katherine G. Nelson, Duane F. Shell, Jenefer Husman, Evan J. Fishman, and Leen-Kiat Soh, "Motivational and SelfRegulated Learning Profiles of Students Taking a Foundational Engineering Course: Learning Profiles of Students in a Foundational Engineering Course,” Journal of Engineering Education, vol. 104, no. 1, pp. 74-100, Jan. 2015.

[10] Peter M. Senge, The Fifth Discipline: The Art \& Practice of The Learning Organization, REV edition. New York: Crown Business, 2006.

[11] Glenda S. Stump, Jenefer Husman, and Marcia Corby, "Engineering Students' Intelligence Beliefs and Learning: Engineering students' intelligence beliefs and learning," Journal of Engineering Education, vol. 103, no. 3, pp. 369-387, Jul. 2014.

[12] L. C. Woollacott, "Dealing with under-preparedness in engineering education. Part 1: Defining the goal. A taxonomy of engineering competency.," Jul. 2008 [Online]. Available: http://wiredspace.wits.ac.za/handle/10539/5027.

[Accessed: 17-May-2016]

[13] L. C. Woollacott, "Taxonomies of Engineering Competencies and Quality Assurance in Engineering Education,” in Engineering Education Quality Assurance, Arun Patil and Peter Gray, Eds. Boston, MA: Springer US, 2009, pp. 257-295 [Online]. Available: http://link.springer.com/10.1007/978-1-4419-0555-0_21.

[Accessed: 16-May-2016]

CEEA16; Paper \#56

Dalhousie University; June 19 - 22, 2016 